\title{
Effect of fascicle composition on ulnar to musculocutaneous nerve transfer (Oberlin transfer) in neonatal brachial plexus palsy
}

\author{
Brandon W. Smith, MD, ${ }^{1}$ Nicholas J. Chulski, ${ }^{2}$ Ann A. Little, MD, ${ }^{2}$ Kate W. C. Chang, MA, MS, ${ }^{1}$ and \\ Lynda J. S. Yang, MD, PhD'
}

Departments of ${ }^{1}$ Neurosurgery and ${ }^{2}$ Neurology, University of Michigan, Ann Arbor, Michigan

OBJECTIVE Neonatal brachial plexus palsy (NBPP) continues to be a problematic occurrence impacting approximately 1.5 per 1000 live births in the United States, with $10 \%-40 \%$ of these infants experiencing permanent disability. These children lose elbow flexion, and one surgical option for recovering it is the Oberlin transfer. Published data support the use of the ulnar nerve fascicle that innervates the flexor carpi ulnaris as the donor nerve in adults, but no analogous published data exist for infants. This study investigated the association of ulnar nerve fascicle choice with functional elbow flexion outcome in NBPP.

METHODS The authors conducted a retrospective study of 13 cases in which infants underwent ulnar to musculocutaneous nerve transfer for NBPP at a single institution. They collected data on patient demographics, clinical characteristics, active range of motion (AROM), and intraoperative neuromonitoring (IONM) (using 4 ulnar nerve index muscles). Standard statistical analysis compared pre- and postoperative motor function improvement between specific fascicle transfer (1-2 muscles for either wrist flexion or hand intrinsics) and nonspecific fascicle transfer (> 2 muscles for wrist flexion and hand intrinsics) groups.

RESULTS The patients' average age at initial clinic visit was 2.9 months, and their average age at surgical intervention was 7.4 months. All NBPPs were unilateral; the majority of patients were female $(61 \%)$, were Caucasian $(69 \%)$, had rightsided NBPP (61\%), and had Narakas grade I or II injuries (54\%). IONM recordings for the fascicular dissection revealed a donor fascicle with nonspecific innervation in $6(46 \%)$ infants and specific innervation in the remaining $7(54 \%)$ patients. At 6 -month follow-up, the AROM improvement in elbow flexion in adduction was $38^{\circ}$ in the specific fascicle transfer group versus $36^{\circ}$ in the nonspecific fascicle transfer group, with no statistically significant difference $(p=0.93)$.

CONCLUSIONS Both specific and nonspecific fascicle transfers led to functional recovery, but that the composition of the donor fascicle had no impact on early outcomes. In young infants, ulnar nerve fascicular dissection places the ulnar nerve at risk for iatrogenic damage. The data from this study suggest that the use of any motor fascicle, specific or nonspecific, produces similar results and that the Oberlin transfer can be performed with less intrafascicular dissection, less time of surgical exposure, and less potential for donor site morbidity.

https://thejns.org/doi/abs/10.3171/2018.3.PEDS17529

KEYWORDS fascicle composition; Oberlin transfer; brachial plexus palsy; elbow; nerve transfer; ulnar nerve; musculocutaneous nerve; peripheral nerve

$\mathrm{N}$ EONATAL brachial plexus palsy (NBPP) affects $1-4$ of 1000 live births in the United States each year, and approximately $10 \%-40 \%$ of these children are left with residual weakness. ${ }^{35}$ Given that a majority of these injuries involve the upper trunk, elbow weakness is a common deficit in these children. The Oberlin, or ulnar to musculocutaneous, nerve transfer is a common method used to restore elbow flexion in patients with deficits in this movement: The indications for the use of this procedure over graft repair remain controversial, and guidelines for use have yet to be established. ${ }^{8,17,24,25,31}$ The literature on nerve transfer in adults supports the utilization of a

ABBREVIATIONS $\mathrm{ADM}=$ abductor digiti minimi; $\mathrm{ADP}=$ adductor pollicis; $\mathrm{AROM}=$ active range of motion; $\mathrm{CMAP}=$ compound muscle action potentials; EMG $=$ electromyography; FCU = flexor carpi ulnaris; FDI = first dorsal interosseous; f-EMG = free-run EMG; IONM = intraoperative neuromonitoring; MRC = Medical Research Council; NBPP = neonatal brachial plexus palsy; $\mathrm{t}-\mathrm{EMG}=$ triggered $\mathrm{EMG} ; \mathrm{TOF}=$ train of four.

SUBMITTED September 22, 2017. ACCEPTED March 14, 2018.

INCLUDE WHEN CITING Published online June 1, 2018; DOI: 10.3171/2018.3.PEDS17529. 
donor fascicle with innervation to the flexor carpi ulnaris $;{ }^{17,25}$ however, no similar literature exists on the optimal innervation of the donor fascicle utilized for nerve transfer in infants with NBPP. Given the increasing evidence of a considerable potential for neuroplasticity in children, ${ }^{11,14}$ we hypothesized that motor fascicle composition does not matter in infants as it does in adults. The ulnar nerve in infants is smaller in diameter and less myelinated, and increased fascicular dissection may result in devascularization and/or iatrogenic injury. Therefore, we report the early functional outcomes after Oberlin transfer in the context of the donor ulnar fascicle composition.

\section{Methods \\ Study Design}

This retrospective cohort study reviewed children diagnosed with NBPP who underwent ulnar fascicle to musculocutaneous nerve transfer using intraoperative monitoring to identify the donor fascicle. A single surgeon performed all procedures at one institution from 2014-2016. Exclusion criteria comprised diagnoses other than NBPP (e.g., trauma) or prior surgery. The University of Michigan institutional review board approved the study.

\section{Surgical Procedure: Indication and Technique}

The Narakas grade was determined by a single surgeon via either 1) physical examination and neurological assessment at approximately 1 week of age or at initial clinical appointment or 2) the mother's or obstetrician's report of child's arm/hand movements at birth. All included Narakas III and IV patients with pan-plexopathy recovered satisfactory preoperative hand function. The decision to pursue Oberlin transfer was made preoperatively, not intraoperatively, because little if any definitive published evidence exists to support the superiority of either nerve graft or transfer technique for nerve reconstruction. All patients who were intended to undergo Oberlin transfer did undergo the nerve transfer. The surgical procedure has been described in detail in many published reports. ${ }^{37}$ The musculocutaneous nerve branch to the biceps was transected proximally adjacent to the takeoff from the parent nerve and coapted in its entirety to an ulnar nerve fascicle. The coracobrachialis and brachialis branches of the musculocutaneous nerve remained undisturbed.

\section{Intraoperative Monitoring}

The cohort was split into 2 groups, those with specific fascicles and those with nonspecific fascicles utilized for the nerve transfer procedure (personal communication, Kate Chang et al., 2017). Patients in the nonspecific fascicle had axons innervating $>2$ muscles (index muscles for ulnar nerve comprised the flexor carpi ulnaris [FCU], first dorsal interosseous [FDI], adductor pollicis [ADP], and abductor digiti minimi [ADM]) for wrist flexion and finger flexion within the fascicle, and those with specific fascicles had innervation to $\leq 2$ muscles. The composition of the fascicle was identified by intraoperative nerve stimulation and quantitative recording.

Intraoperative neuromonitoring (IONM) was performed by monitoring both free-run electromyography
(f-EMG) and triggered EMG (t-EMG). The electrodes were placed sterilely by the surgeon in the corresponding muscles. A train of four (TOF) was obtained by stimulating the contralateral median nerve at the wrist and recording from the contralateral abductor pollicis brevis (APB)-ADM channel. The TOF was performed to ensure the neuromuscular blockade used at intubation had worn off and the patient demonstrated $4 / 4$ twitches in order to reliably monitor EMG. The stimulation parameters of complete nerve and fascicle identification of the ulnar nerve were the following: pulse duration $100 \mu$ sec, repetition rate of $1.1 \mathrm{~Hz}$, and stimulation intensities starting at 0.1 and titrating up to $0.8 \mathrm{~mA}$.

After both the musculocutaneous and the ulnar nerves were exposed, the whole ulnar nerve was stimulated using a concentric bipolar stimulating probe (Medtronic Xomed, Inc., ref 8225351) and compound muscle action potentials (CMAPs) were recorded from the bipolar EMG channels of FCU, FDI, ADP, and ADM. CMAP responses were confirmed by a neurologist in the operating room. Once the baseline CMAP was obtained, the surgeon dissected the ulnar nerve into fascicles. During dissection, f-EMG was recorded and the surgeon was alerted if nerve irritation occurred. Spontaneous EMG was reported when bursts were greater than $30 \mu \mathrm{V}$ and continuous spike trains were elicited from stretching the nerve.

With direct nerve stimulation of an isolated fascicle, tEMG captured responses within the 4 index muscles to identify the relative contribution of the fascicle to each muscle. Direct stimulation of the whole nerve minus the selected fascicle verified that a robust response remained in all 4 index muscles (i.e., that there was redundant innervation of index muscles from other fascicles within the nerve). Free-run EMG monitored the health of the nerve and its fascicles during the exposure and fascicular dissection, with constant assessment for irritability (trains of discharges).

\section{Outcomes of Interest}

Patient demographic data included age at initial appointment, age at operation, sex, ethnicity, side of injury, and Narakas grade. The Narakas grade was determined by the surgeon based on the neurological examination within 1 week of birth or by physician or parent report of the function in the perinatal period. Narakas grade was dichotomized into grade I-II versus grade III-IV. Lesion site and lesion type were recorded at the time of surgery.

One of 2 certified occupational therapists evaluated all patients for active range of motion (AROM) and biceps power on the Medical Research Council (MRC) grading scale preoperatively and 1 year postoperatively. The primary outcomes of the current study were AROM of elbow flexion in adduction, elbow flexion in abduction, forearm supination, and forearm pronation. Secondary outcomes included AROM of shoulder forward flexion, external rotation, internal rotation, abduction, and extension, as well as wrist extension and finger flexion.

\section{Statistical Analysis}

Descriptive statistics were conducted for patient dem- 
TABLE 1. Clinical and demographic characteristics of the 13 patients in the study

\begin{tabular}{|c|c|}
\hline Characteristic & Value \\
\hline \multicolumn{2}{|l|}{ Mean age in months } \\
\hline At initial appointment & $2.9 \pm 1$ \\
\hline At operation & $7.4 \pm 1$ \\
\hline \multicolumn{2}{|l|}{ Sex, $\mathrm{n}(\%)$} \\
\hline Male & $5(39 \%)$ \\
\hline Female & $8(61 \%)$ \\
\hline \multicolumn{2}{|l|}{ Race, n (\%) } \\
\hline Caucasian & $9(69 \%)$ \\
\hline Other & $4(31 \%)$ \\
\hline \multicolumn{2}{|l|}{ NBPP-involved side, n (\%) } \\
\hline Left & $8(61 \%)$ \\
\hline Right & $5(39 \%)$ \\
\hline \multicolumn{2}{|l|}{ Narakas grade, $n(\%)$} \\
\hline$|-| \mid$ & $7(54 \%)$ \\
\hline III-IV & $6(46 \%)$ \\
\hline \multicolumn{2}{|l|}{ Fascicle stimulation, $\mathrm{n}(\%)$} \\
\hline Nonspecific fascicle & $6(46 \%)$ \\
\hline \multicolumn{2}{|l|}{ Specific fascicle } \\
\hline ADP+ADM & $2(15 \%)$ \\
\hline ADM & $2(15 \%)$ \\
\hline ADP+FDI & $1(8 \%)$ \\
\hline FDI & $1(8 \%)$ \\
\hline FCU & $1(8 \%)$ \\
\hline
\end{tabular}

$\mathrm{ADM}=$ abductor digiti minimi; $\mathrm{ADP}=$ adductor pollicis; $\mathrm{FCU}=$ flexor carpi ulnaris; $\mathrm{FDI}$ = first dorsal interosseous.

Mean values are given with SDs.

ographic data and NBPP-related factors. We conducted the Shapiro-Wilk test for normality and applied parametric analysis for this current study. The mean AROM changes for each joint from the initial preoperative visit to the 6-month and 1-year postoperative visits were summarized. Additionally, we present summaries of outcomes by specific versus nonspecific fascicle at 6-month and 1-year follow-up visits.

To evaluate whether there was a 6-month or 1-year outcome difference between the "specific fascicle" and "non- specific fascicle" groups, we compared the 2 groups using the Student t-test for continuous variables, the MannWhitney test for ordinal variables, and the chi-square test or Fisher exact test for categorical variables. Subgroup analysis of AROM by Narakas I-II versus Narakas IIIIV was performed to assess whether the extent of injury would affect 6-month and 1-year AROM outcomes. A p value $<0.05$ was considered as statistically significant. Commercially available software was used for all analyses (SPSS version 22; IBM Corp.).

\section{Results \\ Patient Characteristics}

Thirteen patients underwent Oberlin transfer. Their average age at the time of the operation was $7.4 \pm 1$ months. There were $5(39 \%)$ males and $8(61 \%)$ females within this cohort. All NBPPs were unilateral; 8 (61\%) were left-sided and $5(39 \%)$ were right-sided. The Narakas grade ranged from I to IV; 7 (54\%) cases were grade I-II and 6 (46\%) were grade III-IV. Intraoperative monitoring recordings during the fascicular dissection and selection revealed a donor fascicle with nonspecific innervation of the 4 index muscles in $6(46 \%)$ patients, whereas the other 7 (54\%) patients had donor fascicles with IONM recordings indicating innervation of specific index muscles (Table 1).

\section{Functional Outcomes}

All 13 patients returned for 6-month follow-up. All patients demonstrated significant improvement in elbow flexion AROM (mean $36.92^{\circ}, p=0.005$ ). Elbow flexion in adduction improved from $33^{\circ} \pm 55^{\circ}$ to $68^{\circ} \pm 34^{\circ}$ (p $=$ 0.13 ) with nonspecific fascicle transfer and improved from $51^{\circ} \pm 48^{\circ}$ to $89^{\circ} \pm 55^{\circ}(\mathrm{p}=0.02)$ with specific fascicles (Table 2). There was no statistically significant difference between the magnitude of change in these groups $\left(36^{\circ} \pm\right.$ $49^{\circ}$ vs $38^{\circ} \pm 33^{\circ}, \mathrm{p}=0.93$ ). The entire cohort demonstrated significant improvement in forearm supination AROM (mean $73.75^{\circ}, p=0.003$ ), but statistical significance was lost when the cohort was separated. Forearm supination improved from $-90^{\circ} \pm 0^{\circ}$ to $-6^{\circ} \pm 78^{\circ}(\mathrm{p}=0.07)$ with nonspecific fascicle transfer and from $-77^{\circ} \pm 34^{\circ}$ to $-11^{\circ}$ $\pm 58^{\circ}(\mathrm{p}=0.08)$ with specific fascicles. There was no difference between the magnitudes of change in these groups $\left(84^{\circ} \pm 78^{\circ}\right.$ vs $\left.66^{\circ} \pm 83^{\circ}, \mathrm{p}=0.72\right)$.

TABLE 2. AROM at 6-month follow-up

\begin{tabular}{|c|c|c|c|c|c|c|c|c|c|}
\hline \multirow[b]{2}{*}{ Variable } & \multicolumn{2}{|c|}{ Preop AROM } & \multirow[b]{2}{*}{$\begin{array}{c}\mathrm{p} \\
\text { Value }\end{array}$} & \multicolumn{2}{|c|}{ Postop AROM } & \multirow[b]{2}{*}{$\begin{array}{c}p \\
\text { Value }\end{array}$} & \multicolumn{2}{|c|}{ AROM Improvement* } & \multirow[b]{2}{*}{$\begin{array}{c}p \\
\text { Value }\end{array}$} \\
\hline & $\begin{array}{c}\text { Nonspecific } \\
\text { Fascicle } \\
(n=6)\end{array}$ & $\begin{array}{c}\text { Specific } \\
\text { Fascicle } \\
(n=7)\end{array}$ & & $\begin{array}{c}\text { Nonspecific } \\
\text { Fascicle } \\
(n=6)\end{array}$ & $\begin{array}{c}\text { Specific } \\
\text { Fascicle } \\
(n=7)\end{array}$ & & $\begin{array}{c}\text { Nonspecific } \\
\text { Fascicle } \\
(n=6)\end{array}$ & $\begin{array}{c}\text { Specific } \\
\text { Fascicle } \\
(n=7)\end{array}$ & \\
\hline Elbow flexion in adduction, mean & $33 \pm 55$ & $51 \pm 48$ & 0.52 & $68 \pm 34$ & $89 \pm 55$ & 0.43 & $36 \pm 49$ & $38 \pm 33$ & 0.93 \\
\hline Elbow flexion in abduction, mean & $55 \pm 64$ & $74 \pm 55$ & 0.57 & $110 \pm 25$ & $110 \pm 53$ & 0.99 & $55 \pm 53$ & $36 \pm 47$ & 0.50 \\
\hline MRC strength of biceps, median (range) & $0.5(0-3)$ & $2(0-3)$ & 0.36 & $2.5(2-3)$ & $3(1-4)$ & 0.64 & $1.5(0-3)$ & $1(0-2)$ & 0.35 \\
\hline Forearm supination, mean & $-90 \pm 0$ & $-77 \pm 34$ & 0.38 & $-6 \pm 78$ & $-11 \pm 58$ & 0.91 & $84 \pm 78$ & $66 \pm 83$ & 0.72 \\
\hline Forearm pronation, mean & $90 \pm 0$ & $90 \pm 0$ & - & $90 \pm 0$ & $90 \pm 0$ & - & $0 \pm 0$ & $0 \pm 0$ & - \\
\hline
\end{tabular}

All data are degrees. Mean values are given with SDs.

* Postop AROM vs preop AROM. 
TABLE 3. AROM at 1-year follow-up

\begin{tabular}{|c|c|c|c|c|c|c|c|c|c|}
\hline \multirow[b]{2}{*}{ Variable } & \multicolumn{2}{|c|}{ Preop AROM } & \multirow[b]{2}{*}{$\begin{array}{c}p \\
\text { Value }\end{array}$} & \multicolumn{2}{|c|}{ Postop AROM } & \multirow[b]{2}{*}{$\begin{array}{c}\mathrm{p} \\
\text { Value }\end{array}$} & \multicolumn{2}{|c|}{ AROM Improvement* } & \multirow[b]{2}{*}{$\begin{array}{c}p \\
\text { Value }\end{array}$} \\
\hline & $\begin{array}{c}\text { Nonspecific } \\
\text { Fascicle } \\
(n=4)\end{array}$ & $\begin{array}{c}\text { Specific } \\
\text { Fascicle } \\
(n=5)\end{array}$ & & $\begin{array}{c}\text { Nonspecific } \\
\text { Fascicle } \\
(n=4)\end{array}$ & $\begin{array}{c}\text { Specific } \\
\text { Fascicle } \\
(n=5)\end{array}$ & & $\begin{array}{c}\text { Nonspecific } \\
\text { Fascicle } \\
(n=4)\end{array}$ & $\begin{array}{c}\text { Specific } \\
\text { Fascicle } \\
(n=5)\end{array}$ & \\
\hline Elbow flexion in adduction, mean & $9 \pm 18$ & $34 \pm 47$ & 0.31 & $70 \pm 29$ & $97 \pm 38$ & 0.28 & $61 \pm 21$ & $63 \pm 27$ & 0.92 \\
\hline Elbow flexion in abduction, mean & $23 \pm 45$ & $54 \pm 49$ & 0.36 & $79 \pm 23$ & $126 \pm 33$ & 0.05 & $56 \pm 43$ & $72 \pm 16$ & 0.47 \\
\hline MRC strength of biceps, median (range) & $0.5(0-3)$ & $2(0-3)$ & 0.36 & $2.5(0-3)$ & $3(2-4)$ & 0.32 & $1(0-3)$ & $2(0-3)$ & 0.70 \\
\hline Forearm supination, mean & $-90 \pm 0$ & $-72 \pm 40$ & 0.41 & $15 \pm 30$ & $10 \pm 14$ & 0.75 & $105 \pm 30$ & $82 \pm 48$ & 0.43 \\
\hline Forearm pronation, mean & $90 \pm 0$ & $90 \pm 0$ & - & $90 \pm 0$ & $90 \pm 0$ & - & $0 \pm 0$ & $0 \pm 0$ & - \\
\hline
\end{tabular}

All data are degrees. Mean values are given with SDs.

* Postop AROM vs preop AROM.

Nine $(69 \%)$ patients returned for 1-year clinical followup (Table 3)-4 from the nonspecific fascicle group and 5 from the specific fascicle group. In these remaining patients, there was significant improvement in elbow flexion (mean $62.22^{\circ}, \mathrm{p}=0.001$ ). Elbow flexion in adduction improved from $9^{\circ} \pm 18^{\circ}$ to $70^{\circ} \pm 29^{\circ}(\mathrm{p}=0.01)$ with nonspecific fascicle transfer and from $34^{\circ} \pm 47^{\circ}$ to $97^{\circ} \pm 38^{\circ}$ (p $=0.006$ ) with specific fascicle transfer. Again, there was no statistically significant difference between the magnitudes of change in these groups $\left(61^{\circ} \pm 21^{\circ}\right.$ vs $63^{\circ} \pm 27^{\circ}$, $\mathrm{p}=0.92$ ). The remaining cohort demonstrated significant improvement in forearm supination AROM (mean 92.22 $\mathrm{p}=0.0001$ ). Forearm supination improved from $-90^{\circ} \pm 0^{\circ}$ to $15^{\circ} \pm 30^{\circ}(\mathrm{p}=0.006)$ with nonspecific fascicle transfer and from $-72^{\circ} \pm 40^{\circ}$ to $10^{\circ} \pm 14^{\circ}(\mathrm{p}=0.02)$ with specific fascicle transfer. However, there was no statistically significant difference between the magnitudes of change in these groups $\left(105^{\circ} \pm 30^{\circ}\right.$ vs $\left.82^{\circ} \pm 48^{\circ}, \mathrm{p}=0.43\right)$. Tables 4 and 5 summarize outcomes by fascicle at 6 -month and 1-year follow-up.

Seven (54\%) of the 13 patients were considered to have low Narakas grade (I or II) injuries based on evaluation within 1 week of birth, and $6(46 \%)$ were considered to have high-grade (III or IV) injuries. At the 6-month follow-up visit, elbow flexion in adduction at 6 months had improved by $41^{\circ} \pm 32^{\circ}$ in the grade I-II group and $32^{\circ} \pm$ $49^{\circ}$ in the grade III-IV group (Table 6) (no statistically significant between-groups difference, $p=0.68$ ). Forearm supination improved by $75^{\circ} \pm 59^{\circ}$ in the low-grade group and $73^{\circ} \pm 99^{\circ}$ in the high-grade group; likewise, these improvements did not differ significantly between the groups $(\mathrm{p}=0.96)$. Shoulder abduction improved by $35^{\circ} \pm 40^{\circ}$ in the low-grade patients and $31^{\circ}\left( \pm 29^{\circ}\right)$ in the high-grade patients (Table 7). These two groups did not differ significantly $(p=0.84)$. Finger flexion remained stable in both the low- and the high-grade groups, at $0^{\circ} \pm 0^{\circ}$ and $-1^{\circ} \pm$ $30^{\circ}$, respectively (no significant difference, $\mathrm{p}=0.94$ ).

Of the $9(69 \%)$ patients with 1-year clinical follow-up, $4(44 \%)$ had low-grade lesions and $5(56 \%)$ had high-grade lesions. Elbow flexion in adduction at 12 months improved by $53^{\circ} \pm 26^{\circ}$ in the low-grade group and $70^{\circ} \pm 20^{\circ}$ in the high-grade (Table 8) (no significant difference, $\mathrm{p}=0.29$ ). Forearm supination improved by $95^{\circ} \pm 10^{\circ}$ in the lowgrade group and $90^{\circ} \pm 56^{\circ}$ in the high-grade group (no significant difference, $p=0.87$ ). Shoulder abduction improved by $45^{\circ} \pm 34^{\circ}$ ) in the low-grade group and $55^{\circ} \pm 38^{\circ}$ in the high-grade group (Table 9) (no significant difference, $\mathrm{p}=0.70$ ). Finger flexion remained stable at $0^{\circ} \pm 0^{\circ}$ in the low-grade patients and $-6^{\circ} \pm 13^{\circ}$ in the high-grade group (no significant difference, $\mathrm{p}=0.41$ ). No patient had any wound infection or a decrease in neurological function postoperatively (relative to preoperative function) in this series of cases.

\section{Discussion}

Neonatal brachial plexus palsy continues to be a problematic occurrence in approximately 1.5 per 1000 live births in the United States, with $10 \%-40 \%$ of these infants experiencing permanent disability. ${ }^{5,27,33,43}$ Both nerve grafting procedures and nerve transfers have been used to restore elbow flexion in adults and children. ${ }^{9,16,41,45}$ Nerve transfers, including the Oberlin procedure, that focus on restoration of elbow flexion have demonstrated excellent

TABLE 4. Summaries of outcomes by fascicle at 6-month follow-up

\begin{tabular}{|c|c|c|c|c|c|c|c|}
\hline Variable & Nonspecific Fascicle $(n=6)$ & $A D P+A D M(n=2)$ & $\operatorname{ADM}(n=2)$ & $A D P+F D I(n=1)$ & $\mathrm{FDI}(\mathrm{n}=1)$ & $\operatorname{FCU}(n=1)$ & p Value \\
\hline Elbow flexion in adduction, mean & $68 \pm 34$ & $48 \pm 60$ & $135 \pm 21$ & 140 & 90 & 30 & 0.17 \\
\hline Elbow flexion in abduction, mean & $110 \pm 25$ & $90 \pm 85$ & $150 \pm 0$ & 150 & 50 & 90 & 0.37 \\
\hline $\begin{array}{l}\text { MRC strength of biceps, median } \\
\text { (range) }\end{array}$ & $2.5(2-3)$ & $2(1-3)$ & $3.5(3-4)$ & 3 & 3 & 0 & 0.45 \\
\hline Forearm supination, mean & $-6 \pm 78$ & $-15 \pm 106$ & $13 \pm 18$ & 20 & 0 & -90 & 0.91 \\
\hline Forearm pronation, mean & $90 \pm 0$ & $90 \pm 0$ & $90 \pm 0$ & $90 \pm 0$ & $90 \pm 0$ & $90 \pm 0$ & - \\
\hline
\end{tabular}

All data are degrees. Mean values are given with SDs. 
TABLE 5. Summaries of outcomes by fascicle at 1-year follow-up

\begin{tabular}{|c|c|c|c|c|c|c|}
\hline Variable & Nonspecific Fascicle $(n=4)$ & $A D P+A D M(n=2)$ & $\operatorname{ADM}(n=1)$ & $A D P+F D I(n=1)$ & $\operatorname{FCU}(n=1)$ & $\mathrm{p}$ Value \\
\hline Elbow flexion in adduction, mean & $70 \pm 29$ & $90 \pm 0$ & 150 & 110 & 45 & 0.16 \\
\hline Elbow flexion in abduction, mean & $79 \pm 23$ & $120 \pm 42$ & 150 & 150 & 90 & 0.23 \\
\hline MRC strength of biceps, median (range) & $2.5(0-3)$ & $3(3-3)$ & 4 & 2 & 2 & 0.63 \\
\hline Forearm supination, mean & $15 \pm 30$ & $15 \pm 21$ & 0 & 20 & 0 & 0.96 \\
\hline Forearm pronation, mean & $90 \pm 0$ & $90 \pm 0$ & $90 \pm 0$ & $90 \pm 0$ & $90 \pm 0$ & - \\
\hline
\end{tabular}

All data are degrees. Mean values are given with SDs.

outcomes. $16,17,19,20,23,24,25,29$ However, the use of nerve transfers in NBPP remains controversial, ${ }^{38}$ and the indications, timing, and efficacy of such procedures remain a significant focus of ongoing debate. Similarly, varying paradigms exist regarding the surgical decision making with respect to patients with NBPP. ${ }^{6,21,34}$ Despite the varying paradigms, if an infant has a flail arm or has not recovered enough elbow flexion to bring their hand to their mouth, intervention is indicated..$^{1,10,13,42}$

Over the past 2 decades, the Oberlin transfer has become a mainstay in the attempt to restore elbow flexion $^{17,24,25}$ in adult patients with brachial plexus trauma. Oberlin described the first ulnar fascicle to musculocutaneous branch transfer in 1994, followed by a larger series in $1997 .{ }^{17,25}$ The anatomical proximity of the ulnar and musculocutaneous nerves in the proximal medial arm made the two an ideal pair for nerve transfer. The initial series utilized a fascicle destined for FCU as long as there was redundancy in the remaining nerve. ${ }^{17,25,39}$ Reports have demonstrated excellent functional recovery as well as sparing of the hand intrinsic muscles while utilizing an FCU fascicle in adults. ${ }^{1,936,45}$ This practice has been adopted in the management of NBPP; however, the literature supporting it is sparse. There are several published algorithms for nerve reconstruction in NBPP. We employ the standard indications for surgery previously published. ${ }^{44}$ We recommend nerve reconstruction when functional elbow flexion is lacking and when predicted postoperative outcomes are superior to those expected according to natural history. The timing of surgery is based on the published paradigms for surgical intervention for NBPP. ${ }^{4,22,44}$ In general, nerve transfer operations can occur up to 12 months after birth to allow for optimal conservative re- covery (neuropraxia, axonotmesis) and due to the proximity of the nerve coaptation to the end-organ muscle. The ability to graft depends on nerve roots in continuity with the spinal cord, and the ability to transfer depends on the presence of a healthy donor.

There is concern that extensive dissection of the nerve to isolate a particular fascicle may de-vascularize the donor nerve and/or cause iatrogenic injury. As the ulnar nerve innervates many of the muscles integral to hand function, ${ }^{28}$ the risk of losing hand function in exchange for elbow flexion must be weighed. In cases of grade IIIIV Narakas injuries, hand function must have recovered significantly prior to the operation in order for the patient to be eligible for fascicle transfer from the ulnar nerve. Fortunately, our data demonstrate preservation of testable hand function in all of the infants postoperatively. However, due to the importance of function of the donor nerve, strategies must utilize techniques that maximize both safety and effectiveness of the procedure.

We utilize IONM with varying success in many facets of neurosurgery, including brain tumor, vascular, functional, spine, and peripheral nerve procedures, ${ }^{3,18,30}$ but the use of IONM in neurosurgical procedures remains controversial. For example, recent guidelines on spinal fusion surgery advocate against the utility of nerve monitoring. ${ }^{32}$ In nerve transfer surgery, however, no reports support or dispute the routine use of IONM. Anecdotally, intrafascicular dissection relies heavily on the use of IONM, as it can aid in identification of motor fascicles and also monitor for iatrogenic injury during dissection. Though our data suggest that fascicular motor composition may have no effect on outcomes, the ability to verify that the surgeon has isolated a motor branch in a mixed motor-sensory nerve is of

TABLE 6. Elbow and forearm AROM at 6-month follow-up by Narakas grade group

\begin{tabular}{|c|c|c|c|c|c|c|c|c|c|}
\hline \multirow[b]{2}{*}{ Variable } & \multicolumn{2}{|c|}{ Preop AROM } & \multirow{2}{*}{$\begin{array}{c}p \\
\text { Value }\end{array}$} & \multicolumn{2}{|c|}{ Postop AROM } & \multirow{2}{*}{$\begin{array}{c}p \\
\text { Value }\end{array}$} & \multicolumn{2}{|c|}{ AROM Improvement* } & \multirow{2}{*}{$\begin{array}{c}p \\
\text { Value }\end{array}$} \\
\hline & $|-| \mid(n=7)$ & III-IV $(n=6)$ & & $|-| \mid(n=7)$ & III-IV $(n=6)$ & & $|-| \mid(n=7)$ & III-IV $(n=6)$ & \\
\hline Elbow flexion in adduction, mean & $42 \pm 46$ & $44 \pm 59$ & 0.93 & $83 \pm 44$ & $76 \pm 51$ & 0.80 & $41 \pm 32$ & $32 \pm 49$ & 0.68 \\
\hline Elbow flexion in abduction, mean & $61 \pm 61$ & $70 \pm 59$ & 0.80 & $113 \pm 39$ & $107 \pm 46$ & 0.80 & $51 \pm 57$ & $37 \pm 41$ & 0.61 \\
\hline MRC strength of biceps, median (range) & $2(0-3)$ & $1(0-3)$ & 0.83 & $3(2-3)$ & $2.5(1-4)$ & 0.60 & $1(0-3)$ & $1(0-2)$ & 0.56 \\
\hline Forearm supination, mean & $-90 \pm 0$ & $-75 \pm 37$ & 0.30 & $-15 \pm 59$ & $-3 \pm 73$ & 0.75 & $75 \pm 59$ & $73 \pm 99$ & 0.96 \\
\hline Forearm pronation, mean & $90 \pm 0$ & $90 \pm 0$ & - & $90 \pm 0$ & $90 \pm 0$ & - & $0 \pm 0$ & $0 \pm 0$ & - \\
\hline
\end{tabular}

Cases were grouped by Narakas grade (as determined within 1 week of the patient's birth) into low (I-II) and high (III-IV) grades for extent of injury. All data are degrees. Mean values are given with SDs.

* Postop AROM vs preop AROM. 
TABLE 7. Shoulder and hand AROM at 6-month follow-up by Narakas grade group

\begin{tabular}{|c|c|c|c|c|c|c|c|c|c|}
\hline \multirow[b]{2}{*}{ Variable } & \multicolumn{2}{|c|}{ Preop AROM } & \multirow{2}{*}{$\begin{array}{c}p \\
\text { Value }\end{array}$} & \multicolumn{2}{|c|}{ Postop AROM } & \multirow{2}{*}{$\begin{array}{c}p \\
\text { value }\end{array}$} & \multicolumn{2}{|c|}{ AROM Improvement* } & \multirow{2}{*}{$\begin{array}{c}p \\
\text { value }\end{array}$} \\
\hline & $|-| \mid(n=7)$ & III-IV $(n=6)$ & & $|-| \mid(n=7)$ & III-IV $(n=6)$ & & $|-| \mid(n=7)$ & III-IV $(n=6)$ & \\
\hline Shoulder flexion & $87 \pm 53$ & $41 \pm 35$ & 0.09 & $112 \pm 48$ & $73 \pm 44$ & 0.16 & $25 \pm 31$ & $33 \pm 46$ & 0.73 \\
\hline Shoulder abduction & $62 \pm 55$ & $31 \pm 34$ & 0.25 & $97 \pm 66$ & $62 \pm 39$ & 0.28 & $35 \pm 40$ & $31 \pm 29$ & 0.84 \\
\hline Shoulder extension & $7 \pm 19$ & $-3 \pm 14$ & 0.28 & $9 \pm 19$ & $2 \pm 4$ & 0.40 & $1 \pm 29$ & $5 \pm 14$ & 0.79 \\
\hline Shoulder exorotation in adduction & $-56 \pm 44$ & $-83 \pm 18$ & 0.18 & $3 \pm 53$ & $-36 \pm 57$ & 0.23 & $59 \pm 43$ & $47 \pm 50$ & 0.65 \\
\hline Shoulder exorotation in abduction & $-51 \pm 48$ & $-45 \pm 49$ & 0.82 & $29 \pm 33$ & $-25 \pm 47$ & 0.03 & $81 \pm 45$ & $20 \pm 35$ & 0.02 \\
\hline Shoulder endorotation in adduction & $70 \pm 0$ & $70 \pm 0$ & - & $70 \pm 0$ & $70 \pm 0$ & - & $0 \pm 0$ & $0 \pm 0$ & - \\
\hline Shoulder endorotation in abduction & $70 \pm 0$ & $70 \pm 0$ & - & $70 \pm 0$ & $63 \pm 16$ & 0.36 & $0 \pm 0$ & $-7 \pm 16$ & 0.36 \\
\hline Wrist extension & $27 \pm 73$ & $31 \pm 33$ & 0.91 & $56 \pm 27$ & $40 \pm 31$ & 0.33 & $29 \pm 51$ & $9 \pm 46$ & 0.47 \\
\hline Finger flexion & $90 \pm 0$ & $83 \pm 18$ & 0.36 & $90 \pm 0$ & $82 \pm 20$ & 0.36 & $0 \pm 0$ & $-1 \pm 30$ & 0.94 \\
\hline
\end{tabular}

Cases were grouped by Narakas grade (as determined within 1 week of the patient's birth) into low (I-II) and high (III-IV) grades for extent of injury. Data are mean ( \pm SD) degrees.

* Postop AROM vs preop AROM.

TABLE 8. Elbow and forearm AROM at 1-year follow-up by Narakas grade group

\begin{tabular}{|c|c|c|c|c|c|c|c|c|c|}
\hline \multirow[b]{2}{*}{ Variable } & \multicolumn{2}{|c|}{ Preop AROM } & \multirow{2}{*}{$\begin{array}{c}p \\
\text { Value }\end{array}$} & \multicolumn{2}{|c|}{ Postop AROM } & \multirow{2}{*}{$\begin{array}{c}p \\
\text { Value }\end{array}$} & \multicolumn{2}{|c|}{ AROM Improvement* } & \multirow{2}{*}{$\begin{array}{c}p \\
\text { Value }\end{array}$} \\
\hline & $|-| \mid(n=4)$ & III-IV $(n=5)$ & & $I-I \mid(n=4)$ & III-IV $(n=5)$ & & $|-| \mid(n=4)$ & III-IV $(n=5)$ & \\
\hline Elbow flexion in adduction, mean & $20 \pm 40$ & $25 \pm 39$ & 0.86 & $73 \pm 33$ & $95 \pm 37$ & 0.38 & $53 \pm 26$ & $70 \pm 20$ & 0.29 \\
\hline Elbow flexion in abduction, mean & $23 \pm 45$ & $54 \pm 49$ & 0.36 & $94 \pm 43$ & $114 \pm 33$ & 0.45 & $71 \pm 23$ & $60 \pm 37$ & 0.61 \\
\hline MRC strength of biceps, median (range) & $0(0-2)$ & $1(0-3)$ & 0.34 & $2(0-3)$ & $3(2-4)$ & 0.10 & $2(0-3)$ & $2(0-3)$ & 0.99 \\
\hline Forearm supination, mean & $-90 \pm 0$ & $-72 \pm 40$ & 0.41 & $5 \pm 10$ & $18 \pm 27$ & 0.39 & $95 \pm 10$ & $90 \pm 56$ & 0.87 \\
\hline Forearm pronation, mean & $90 \pm 0$ & $90 \pm 0$ & - & $90 \pm 0$ & $90 \pm 0$ & - & $0 \pm 0$ & $0 \pm 0$ & - \\
\hline
\end{tabular}

Cases were grouped by Narakas grade (as determined within 1 week of the patient's birth) into low (I-II) and high (III-IV) grades for extent of injury. All data are degrees. Mean values are given with SDs.

* Postop AROM vs preop AROM.

TABLE 9. Shoulder and hand AROM at 1-year follow-up by Narakas grade group

\begin{tabular}{|c|c|c|c|c|c|c|c|c|c|}
\hline \multirow[b]{2}{*}{ Variable } & \multicolumn{2}{|c|}{ Preop AROM } & \multirow{2}{*}{$\begin{array}{c}p \\
\text { Value }\end{array}$} & \multicolumn{2}{|c|}{ Postop AROM } & \multirow{2}{*}{$\begin{array}{c}p \\
\text { Value }\end{array}$} & \multicolumn{2}{|c|}{ AROM Improvement* } & \multirow{2}{*}{$\begin{array}{c}p \\
\text { Value }\end{array}$} \\
\hline & $|-| \mid(n=4)$ & III-IV $(n=5)$ & & $|-| \mid(n=4)$ & III-IV (n= 5) & & $|-| \mid(n=4)$ & III-IV (n= 5) & \\
\hline Shoulder flexion & $71 \pm 64$ & $35 \pm 35$ & 0.31 & $101 \pm 43$ & $101 \pm 46$ & 0.99 & $30 \pm 30$ & $66 \pm 14$ & 0.05 \\
\hline Shoulder abduction & $48 \pm 62$ & $33 \pm 37$ & 0.68 & $93 \pm 46$ & $88 \pm 59$ & 0.91 & $45 \pm 34$ & $55 \pm 38$ & 0.70 \\
\hline Shoulder extension & $13 \pm 25$ & $2 \pm 4$ & 0.47 & $5 \pm 10$ & $0 \pm 0$ & 0.39 & $-8 \pm 30$ & $-2 \pm 4$ & 0.74 \\
\hline Shoulder exorotation in adduction & $-68 \pm 45$ & $-81 \pm 20$ & 0.56 & $-25 \pm 44$ & $-7 \pm 27$ & 0.47 & $43 \pm 49$ & $74 \pm 31$ & 0.28 \\
\hline Shoulder exorotation in abduction & $-68 \pm 45$ & $-36 \pm 49$ & 0.36 & $-18 \pm 49$ & $7 \pm 39$ & 0.43 & $50 \pm 47$ & $43 \pm 29$ & 0.79 \\
\hline Shoulder endorotation in adduction & $70 \pm 0$ & $70 \pm 0$ & - & $70 \pm 0$ & $70 \pm 0$ & - & $0 \pm 0$ & $0 \pm 0$ & - \\
\hline Shoulder endorotation in abduction & $70 \pm 0$ & $70 \pm 0$ & - & $70 \pm 0$ & $70 \pm 0$ & - & $0 \pm 0$ & $0 \pm 0$ & - \\
\hline Wrist extension & $-5 \pm 87$ & $37 \pm 33$ & 0.42 & $39 \pm 29$ & $58 \pm 18$ & 0.26 & $44 \pm 70$ & $21 \pm 42$ & 0.56 \\
\hline Finger flexion & $90 \pm 0$ & $90 \pm 0$ & - & $90 \pm 0$ & $84 \pm 13$ & 0.41 & $0 \pm 0$ & $-6 \pm 13$ & 0.41 \\
\hline
\end{tabular}

Cases were grouped by Narakas grade (as determined within 1 week of the patient's birth) into low (I-II) and high (III-IV) grades for extent of injury. Data are mean ( \pm $\mathrm{SD})$ degrees.

* Postop AROM vs preop AROM. 
the utmost importance. Similarly, monitoring of the health of the nerve during intrafascicular dissection assures the surgeon that the very important hand function conferred by the parent ulnar nerve is preserved.

Our study evaluated functional outcomes in patients with NBPP undergoing the Oberlin transfer, specifically focusing on the question of whether the composition of the donor fascicle changes outcomes or whether any motor fascicle is an appropriate donor for nerve transfer. As in previous studies, ${ }^{4,15,26}$ we again demonstrate the utility of the ulnar fascicle to musculocutaneous nerve transfer in NBPP (personal communication, Kate Chang, 2017), but we were unable to demonstrate superiority of any single fascicle or specific fascicles of the ulnar nerve in conferring elbow flexion or forearm supination. We speculate that this is due to the redundancy of FCU fascicles within the donor nerve, increased regenerative capacity in children, and also the increased neuroplasticity in the developing infantile brain. ${ }^{11,12,14}$ There are many hypotheses as to why we see better functional recovery in pediatric patients compared with adults with similar pathology in neurosurgery. In nerve surgery specifically, experimental data show that the regenerative potential of a nerve is age dependent ${ }^{40}$ Though neuroplasticity remains in adulthood, NBPP causes large amounts of reorganization of the developing brain, and the effect can be so strong that a shifting of language dominance can be noted in patients with right-sided lesions. ${ }^{2,7}$ The ability for a young nerve to grow and reinnervate muscle coupled with the incredible plasticity potential in this age group could be the reason that we did not demonstrate any appreciable effect of the motor composition of the donor fascicle. Although our cohort demonstrated improvement in shoulder function, we do not imply a direct association of the ulnar to musculocutaneous nerve transfer on shoulder abduction. The upper limb acts as a series of connected articulations, but the joint of action for the Oberlin transfer is the elbow. The improvements in shoulder function are more likely due to other directed interventions.

The limitations of this study include the number of patients in the outcomes data and a lack of randomization. Such a small sample size makes interpretation of data difficult; however, there were no strong differences in mean values in the major functional outcomes. Though the numbers are low, these numbers are improvements on literature previously published regarding surgical intervention on pediatric brachial plexus palsy.

\section{Conclusions}

This study demonstrates the first investigation of fascicle composition in the ulnar to musculocutaneous nerve transfer in infants with NBPP. The data demonstrate no appreciable differences in functional outcomes based on fascicle composition. Therefore, this evidence supports the practice of transferring the initial isolated motor fascicle given that there is redundancy within the remaining ulnar nerve.

\section{References}

1. Ali ZS, Heuer GG, Faught RWF, Kaneriya SH, Sheikh UA,
Syed IS, et al: Upper brachial plexus injury in adults: comparative effectiveness of different repair techniques. J Neurosurg 122:195-201, 2015

2. Auer T, Pinter S, Kovacs N, Kalmar Z, Nagy F, Horvath RA, et al: Does obstetric brachial plexus injury influence speech dominance? Ann Neurol 65:57-66, 2009

3. Bertani G, Fava E, Casaceli G, Carrabba G, Casarotti A, Papagno C, et al: Intraoperative mapping and monitoring of brain functions for the resection of low-grade gliomas: technical considerations. Neurosurg Focus 27(4):E4, 2009

4. Borschel GH, Clarke HM: Obstetrical brachial plexus palsy. Plast Reconstr Surg 124 (1 Suppl):144e-155e, 2009

5. Chang KWC, Ankumah NAE, Wilson TJ, Yang LJS, Chauhan SP: Persistence of neonatal brachial plexus palsy associated with maternally reported route of delivery: review of 387 cases. Am J Perinatol 33:765-769, 2016

6. Clarke HM, Curtis CG: An approach to obstetrical brachial plexus injuries. Hand Clin 11:563-581, 1995

7. Feng JT, Liu HQ, Xu JG, Gu YD, Shen YD: Differences in brain adaptive functional reorganization in right and left total brachial plexus injury patients. World Neurosurg 84:702708, 2015

8. Figueiredo RM, Grechi G, Gepp RA: Oberlin's procedure in children with obstetric brachial plexus palsy. Childs Nerv Syst 32:1085-1091, 2016

9. Garg R, Merrell GA, Hillstrom HJ, Wolfe SW: Comparison of nerve transfers and nerve grafting for traumatic upper plexus palsy: a systematic review and analysis. J Bone Joint Surg Am 93:819-829, 2011

10. Gilbert A, Tassin JL: [Surgical repair of the brachial plexus in obstetric paralysis.] Chirurgie 110:70-75, 1984 (Fr)

11. Ismail FY, Fatemi A, Johnston MV: Cerebral plasticity: Windows of opportunity in the developing brain. Eur J Paediatr Neurol 21:23-48, 2017

12. Johnston MV: Plasticity in the developing brain: implications for rehabilitation. Dev Disabil Res Rev 15:94-101, 2009

13. Kawabata H, Masada K, Tsuyuguchi Y, Kawai H, Ono K, Tada R: Early microsurgical reconstruction in birth palsy. Clin Orthop Relat Res (215):233-242, 1987

14. Kolb B, Gibb R: Brain plasticity and behaviour in the developing brain. J Can Acad Child Adolesc Psychiatry 20:265276, 2011

15. Kozin SH: Nerve transfers in brachial plexus birth palsies: indications, techniques, and outcomes. Hand Clin 24:363$376, v, 2008$

16. Little KJ, Zlotolow DA, Soldado F, Cornwall R, Kozin SH: Early functional recovery of elbow flexion and supination following median and/or ulnar nerve fascicle transfer in upper neonatal brachial plexus palsy. J Bone Joint Surg Am 96:215-221, 2014

17. Loy S, Bhatia A, Asfazadourian H, Oberlin C: [Ulnar nerve fascicle transfer onto to the biceps muscle nerve in $\mathrm{C} 5-\mathrm{C} 6$ or C5-C6-C7 avulsions of the brachial plexus. Eighteen cases.] Ann Chir Main Memb Super 16:275-284, 1997 (Fr)

18. Macdonald DB: Intraoperative motor evoked potential monitoring: overview and update. J Clin Monit Comput 20:347377, 2006

19. Mackinnon SE, Novak CB: Nerve transfers. New options for reconstruction following nerve injury. Hand Clin 15:643666, ix, 1999

20. Mackinnon SE, Novak CB, Myckatyn TM, Tung TH: Results of reinnervation of the biceps and brachialis muscles with a double fascicular transfer for elbow flexion. J Hand Surg Am 30:978-985, 2005

21. Malessy MJ, Pondaag W: Neonatal brachial plexus palsy with neurotmesis of C5 and avulsion of C6: supraclavicular reconstruction strategies and outcome. J Bone Joint Surg Am 96:e174, 2014

22. Malessy MJ, Pondaag W, Yang LJ, Hofstede-Buitenhuis SM, 
le Cessie S, van Dijk JG: Severe obstetric brachial plexus palsies can be identified at one month of age. PLoS One 6:e26193, 2011

23. Nath RK, Mackinnon SE: Nerve transfers in the upper extremity. Hand Clin 16:131-139, ix, 2000

24. Oberlin C, Ameur NE, Teboul F, Beaulieu JY, Vacher C: Restoration of elbow flexion in brachial plexus injury by transfer of ulnar nerve fascicles to the nerve to the biceps muscle. Tech Hand Up Extrem Surg 6:86-90, 2002

25. Oberlin C, Béal D, Leechavengvongs S, Salon A, Dauge MC, Sarcy JJ: Nerve transfer to biceps muscle using a part of ulnar nerve for C5-C6 avulsion of the brachial plexus: anatomical study and report of four cases. J Hand Surg Am 19:232-237, 1994

26. O'Grady KM, Power HA, Olson JL, Morhart MJ, Harrop AR, Watt MJ, et al: Comparing the efficacy of triple nerve transfers with nerve graft reconstruction in upper trunk obstetrical brachial plexus injury. Plast Reconstr Surg 140:747-756, 2017

27. Pondaag W, Malessy MJ, van Dijk JG, Thomeer RT: Natural history of obstetric brachial plexus palsy: a systematic review. Dev Med Child Neurol 46:138-144, 2004

28. Ray WZ, Chang J, Hawasli A, Wilson TJ, Yang L: Motor nerve transfers: a comprehensive review. Neurosurgery 78:1-26, 2016

29. Ray WZ, Pet MA, Yee A, Mackinnon SE: Double fascicular nerve transfer to the biceps and brachialis muscles after brachial plexus injury: clinical outcomes in a series of 29 cases. J Neurosurg 114:1520-1528, 2011

30. Sanai N, Mirzadeh Z, Berger MS: Functional outcome after language mapping for glioma resection. N Engl J Med 358:18-27, 2008

31. Sedain G, Sharma MS, Sharma BS, Mahapatra AK: Outcome after delayed Oberlin transfer in brachial plexus injury. Neurosurgery 69:822-828, 2011

32. Sharan A, Groff MW, Dailey AT, Ghogawala Z, Resnick DK, Watters WC III, et al: Guideline update for the performance of fusion procedures for degenerative disease of the lumbar spine. Part 15: electrophysiological monitoring and lumbar fusion. J Neurosurg Spine 21:102-105, 2014

33. Sheffler LC, Lattanza L, Hagar Y, Bagley A, James MA: The prevalence, rate of progression, and treatment of elbow flexion contracture in children with brachial plexus birth palsy. J Bone Joint Surg Am 94:403-409, 2012

34. Somashekar DK, Wilson TJ, DiPietro MA, Joseph JR, Ibrahim M, Yang LJS, et al: The current role of diagnostic imaging in the preoperative workup for refractory neonatal brachial plexus palsy. Childs Nerv Syst 32:1393-1397, 2016

35. Squitieri L, Steggerda J, Yang LJS, Kim HM, Chung KC: A national study to evaluate trends in the utilization of nerve reconstruction for treatment of neonatal brachial plexus palsy. Plast Reconstr Surg 127:277-283, 2011

36. Suzuki O, Sunagawa T, Yokota K, Nakashima Y, Shinomiya $\mathrm{R}$, Nakanishi $\mathrm{K}$, et al: Use of quantitative intra-operative electrodiagnosis during partial ulnar nerve transfer to restore elbow flexion: the treatment of eight patients following a brachial plexus injury. J Bone Joint Surg Br 93:364-369, 2011

37. Teboul F, Kakkar R, Ameur N, Beaulieu JY, Oberlin C: Transfer of fascicles from the ulnar nerve to the nerve to the biceps in the treatment of upper brachial plexus palsy. J Bone Joint Surg Am 86-A:1485-1490, 2004

38. Tse R, Marcus JR, Curtis CG, Dupuis A, Clarke HM: Suprascapular nerve reconstruction in obstetrical brachial plexus palsy: spinal accessory nerve transfer versus C5 root grafting. Plast Reconstr Surg 127:2391-2396, 2011

39. Tubbs RS, Custis JW, Salter EG, Blount JP, Oakes WJ, Wellons JC III: Quantitation of and landmarks for the muscular branches of the ulnar nerve to the forearm for application in peripheral nerve neurotization procedures. J Neurosurg 104:800-803, 2006

40. Vaughan DW: Effects of advancing age on peripheral nerve regeneration. J Comp Neurol 323:219-237, 1992

41. Wang JP, Rancy SK, Lee SK, Feinberg JH, Wolfe SW: Shoulder and elbow recovery at 2 and 11 years following brachial plexus reconstruction. J Hand Surg Am 41:173-179, 2016

42. Waters PM: Comparison of the natural history, the outcome of microsurgical repair, and the outcome of operative reconstruction in brachial plexus birth palsy. J Bone Joint Surg Am 81:649-659, 1999

43. Wilson TJ, Chang KWC, Chauhan SP, Yang LJS: Peripartum and neonatal factors associated with the persistence of neonatal brachial plexus palsy at 1 year: a review of 382 cases. $\mathbf{J}$ Neurosurg Pediatr 17:618-624, 2016

44. Wilson TJ, Chang KWC, Yang LJS: Prediction algorithm for surgical intervention in neonatal brachial plexus palsy. Neurosurgery 82:335-342, 2018

45. Yang LJS, Chang KWC, Chung KC: A systematic review of nerve transfer and nerve repair for the treatment of adult upper brachial plexus injury. Neurosurgery 71:417-429, 2012

\section{Disclosures}

The authors report no conflict of interest concerning the materials or methods used in this study or the findings specified in this paper.

\section{Author Contributions}

Conception and design: all authors. Acquisition of data: Yang, Chang. Analysis and interpretation of data: Yang, Smith, Little, Chang. Drafting the article: all authors. Critically revising the article: all authors. Reviewed submitted version of manuscript: all authors. Approved the final version of the manuscript on behalf of all authors: Yang. Statistical analysis: Yang, Smith, Chang. Administrative/technical/material support: Yang, Chang. Study supervision: Yang, Little.

\section{Correspondence}

Lynda J. S. Yang: University of Michigan, Ann Arbor, MI. ljsyang@med.umich.edu. 